\title{
Simulation modelling of the municipal sanatorium-tourist branch
}

\author{
Andrey Kopyrin ${ }^{1, *}$ \\ ${ }^{1}$ Sochi state university, Sovetskaya st., 26a, Sochi, 354000, Russia,
}

\begin{abstract}
This issue is devoted to urban dynamics research and modelling of Sochi resort region. Sochi is a Russian resort city, situated near the southern Russian border. Under current conditions, there is a need to work out new approaches to management that can aim at expanding the city's capacity to develop itself and enhance the quality of life of its residents. One of them is the use of long-term forecasting in the practice of the city's government, which would align the interests of the city's business, authorities, and residents. The imitation modelling method ensures the iterative process of developing the model which is characterized by the gradual broadening of knowledge about the system with the participation of experts and specialists in the domain area. The imitation model for the city does not provide an optimum solution unlike the classic solution for optimization objectives, but it is an auxiliary means, convenient to use for local self-government officials, of searching for solutions to certain issues related to the city's social-economic development. On this model were made several computational experiments, and scenario analysis, which results can provide the decision maker with the needed information and forecast data.
\end{abstract}

\section{Introduction}

For the last decades, tourism has shown impressive growth worldwide that promoted increase of research interest in this area. Tourism as an industry generates considerable multiplier effect [1]. It contributes to the creation of jobs and the development of small businesses, as well as growth in related industries. Development of tools allowing explaining and predicting behaviour of tourist industry on short and medium-term prospect will help to solve a wide range of applied tasks. A key component of such a tool is the model of demand for tourist and recreational product in general, and for health-services in particular. The development of such a model is especially actual for the Sochi-city because of its variety of recreational resources and current medical and health specialization.

Research object is the tourist and recreational complex of Sochi-city.

Research objective is the analysis of existing approaches to modelling and forecasting of demand for tourist services and rational selection of the approach available for practical use in forecasting the demand for health tourism.

To achieve this goal it is necessary to solve a number of tasks:

\footnotetext{
*Corresponding author: kopyrin_a@mail.ru
} 
- to analyse and systematize data on available techniques and technologies of modelling of demand for tourist services;

- to give a technique for the subsequent development of model of demand for tourism;

- to construct and verify model of demand tourist services;

- to carry out the scenario analysis and forecasting of development of Sochi-city.

\section{Discussion}

\subsection{Degree of a problem.}

Since the modelling of demand for tourist services is an important part of most research in this area, a large number of works has been devoted to the problem. According to [2], it is possible to make the following classification of such models.

1. Models based on time series

2. Econometric models

3. Models of "soft" computing.

Regression models explain the behaviour of the studied system proceeding from retrospective data that is the statistics for already expired period. Having constructed dependence on the available data, it is possible to predict the future values of studied variables. This type of model is the most widely spred in the study of tourism demand. The most popular among researchers is Autoregressive Integrated Moving - Average Model (ARIMA), which was first proposed in [3].

This model combines stochastic methods and models of a moving average. Stochastic models are designed using the concepts and methods of the casual processes theory. In particular, in these models future values are calculated based on past expressions. These data are supplemented by considering combinations of several casual processes (called white noise) through a technique of a moving average.

According to [4] various modifications of this technique were used in the majority (more than 50\%) of works on modelling tourism demand, since 80 th years of the XX century.

Modifications of this method can be various. For seasonality modelling, which is especially important for decision-makers in this area, it is possible to apply the SARIMA model, which considers this factor, but more demanding to the basic data. For researching several trends at once, besides the main variable multidimensional models are used. However, in this case it is necessary to increase the forecast accuracy to solve the problem of cross-correlation between the structures of parallel simulated processes.

Other expansion of the time series analysis is generalized autoregressive conditional heteroskedasticity (GARCH) model. Time row is heteroscedastic if its volatility is a function of time. GARCH widely used in financially context modelling for research volatility of time series. In [5] three multidimensional GARCH models were applied to studying of tourism demand variability and consequences of various shocks. It has been established that tourist demand considerably depends on model conditions.

One of the main advantages of econometric models over time series models consists in their ability to analyse the relationship between the dependent variables of demand and to identify influencing factors. Econometric analysis performs a useful role, but is not a tool for forecasting. These models combine the existing empirical and theoretical knowledge (econometric functions) and allow identifying perspective research strategy.

As to influencing factors, recent econometric studies of tourism demand showed that the income of tourists, price compression, prices of competitors (substitute prices) and exchange rates are the most important determinants of tourism demand. These factors 
define a competitive approach to formation of the prices. Therefore, "embedding" of suitable econometric models in the evaluation demand is important for theoretical researches and for practice.

To avoid obtaining false regression that often occurs using the traditional regression analysis, based on the method of ordinary least squares (OLS), new modern econometric methods are developed. In particular, there are Autoregressive Distributed Lag Model (ADLM), Error Correction Model (ECM), vector autoregressive model (VAR), TimeVarying Parameter model (TVP). Except the VAR model, the listed models are based on use of the single equation connecting explaining variables included in model.

The Almost Ideal Demand System (AIDS) has been developed by Diton and Muellbauer [6]. Unlike the econometric models based on one equation, AIDS uses a system of equations describing the demand in a number of neighbouring recreational market objects, and considers the expenditure as the dependent variable. AIDS has sufficiently convincing economic justification, but there is no data about its significant advantage is in the forecast. The initial model is static and cannot be used to simulate indicators in dynamics.

In addition to time series models and econometric models currently several new forecasting techniques are used such as simulation and artificial intelligence techniques (AI). These new quantitative methods are based on heuristic technicians, for example, genetic algorithms, fuzzy logic and artificial neural networks.

The main advantage of AI techniques is that they do not require any preliminary or additional information, such as distribution and probability. These AI techniques have been applied to forecasting in tourism in a number of recent studies.

Artificial neural networks (ANN) is a technology that tries to simulate the processes of human brain learning [7]. The unique features of the ANN, such as the ability to adapt for incompleteness of data and nonlinearity of approximated function, make this method a useful alternative of classical (statistical) regression model of forecasting. Empirical data [8] show that ANN in general surpass classical time series model and multiple regression model in the sphere of forecasting tourism.

Despite satisfactory results of forecasting, ANN method has no systematic procedure for constructing the model, and reliability of forecasting model is usually reached by tests, mistakes and experiments $[9,10]$.

Methods of fuzzy calculations show good predictive capability for short time series with a limited period of past observations.

Heuristic genetic algorithms (GA) are based on evolutionary ideas of natural selection and genetics. GA are usually recognized as an optimization approach. Recent studies, for example [11], have shown that these algorithms are suitable for explaining the changes in the tourism demand.

Modelling techniques choice is determined by a set of factors. Among them are the following: availability of data, parameters of time series forecasting horizon, etc. Also tourism demand models are classified by direction (arrival place, departure place) and periodization of the original data (year, quarter, month).

\subsection{Specifics of the research object and modelling technique}

Despite a wide range of possible modelling techniques, there are objective difficulties in health tourism studies. Now there are no standard indicators of health tourism, separating it from the total volume of tourist services. The available statistics does not represent data on the vacationers who have arrived on resorts for the medical purpose. This transfers model to an area of sociological polls and expert estimates. This feature reduces the quality of possible regression and econometric models, simply because there is no objective data for 
their construction. The presence of this kind of uncertainty makes simulation the most suitable technique because it allows reflecting adequately structure of considered difficult dynamic system, to introduce in model uncertainty factors. The method of simulation provides iterative process of development of the model, being characterised with gradual increasing knowledge of system with participation of experts of subject domain.

Currently, there are three main techniques of simulation.

1. System dynamics - a method of studying of processes dynamics in complex systems. The special attention in it is given to the integration and modelling of feedback in the system. The system-dynamic models are usually given in the form of flow diagrams, consisting of levels, and rates between them, loops of feedback and auxiliary variables, which are then translated into a system of differential equations.

2. Discrete-event, or process modelling - a method of describing the processes occurring in the system, in the form of a sequence of operations over the demands representing people, documents, vehicles, packages of data etc. Actually, it is way of defining queuing systems (QS) of any complexity. Such models are described by blocks processing demands according to a set of parameters, and connections between them, defining operations sequence.

3. Agent-based modelling - a method of the description of system as sets of independent objects, each of which can follow their own rules, interact with each other and with their environment. For developing agent-based models various designs can be used, including program code, but the most convenient way to specify behaviour of agents is statecharts.

However there is something that unites all agent-based models: they are essentially decentralized. Unlike system dynamics or discrete-event models, there is no such place, where the behaviour (dynamics) of system as a whole centrally would be defined. Analyst determines behaviour at individual level, and the global behaviour emerges as a result of many (tens, hundreds, thousands, millions) agents, each of which follows own rules.

Each agent communicates with other agents forming the environment and because of functioning, can change both environment, and the behaviour. Typically, in such systems, there is no global centralized management; agents are functioning in its own laws asynchronously. The global behaviour of a multi-agent model can be viewed as the dynamics of aggregate indicators describing some common features of working agents.

These approaches are used in different situations. For example, the system dynamics deals with global dependencies and is used at high level of abstraction. Discrete-event models generally belong to the average level of abstraction when the physical extent of objects, speeds, distances are not important and the main parameter for such models is time. Agent-based models have a wide range of applications and are used from physical level of abstraction to the strategic.

Tourism industry combines indicators that interact at a high level of abstraction, so as a research method we choose system dynamics.

\subsection{Building a simulation model}

Creation of system dynamics model is based on the following algorithm:

1. Systematization and formalization of data.

2. Construction of cognitive models.

3. Construction of flow diagrams.

4. Verification of the received model

5. Sensitivity analysis and structure optimization of the model.

6. Simulation modelling and carrying out computing experiments.

7. Analysis of simulation results. 
Cognitive (or descriptive) model of the tourism market is as follows (Fig. 1).

A key factor determining the demand for tourism services is gross domestic product (GDP) of Russia. It defines the population income, which in turn affect household spending. Spending on tourist trips is a part of the total spending of households and directly depends on it. In addition, household spending determines the total spending of tourists on vacation. GDP also directly influences an incidence in the country (or disease fixation level), as well as the average lifespan. These factors determine the need for medical and health services and the impact on the percentage of travellers who demand the health services. All factors described above define demand for tourism services.

The supply is defined by recreational resources of the region, and the number of seats in the accommodation facilities. These variables depend on the investment in tourism, which are determined by the general level of the gross regional product of the region.

Equilibrium in the regional market of tourism services is achieved through pricing. Cost of a tourist product is influenced by the cost of labour in the industry, the transport component depreciation. Also significant factors are the cost of similar services abroad and the real rate of national currency. These factors determine the price attractiveness of the resort, which along with the recreational appeal determines the number of tourists in the region.

After formalizing the model takes the form shown in Fig. 1.

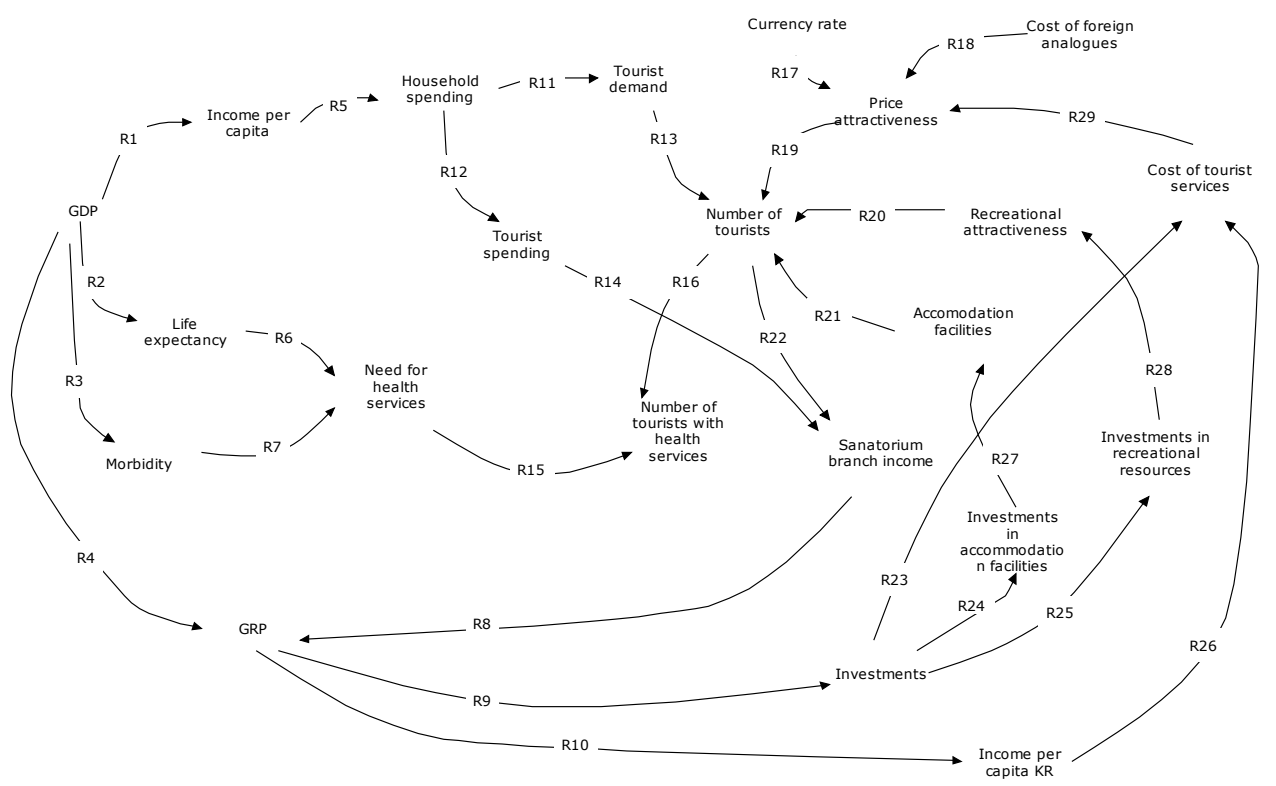

Fig. 1. Caption of the Figure 1. Below the figure.

Description of cognitive model indicators is presented in Table 1, and relations - in Table 2. 
Table 1. Cognitive model indicators

\begin{tabular}{|c|c|c|}
\hline Indicator & Description & $\begin{array}{c}\text { Unit of } \\
\text { measurement }\end{array}$ \\
\hline GDP & $\begin{array}{l}\text { Gross domestic product of Russia, given in prices of } \\
\qquad 2006 .\end{array}$ & ruble \\
\hline Life expectancy & Life expectancy in the year under review & years \\
\hline Morbidity & The number of cases per thousand in the reporting period & - \\
\hline Income per capita & Average cash income per capita & ruble \\
\hline $\begin{array}{c}\text { Household } \\
\text { spending }\end{array}$ & Final consumption expenditure of households & ruble \\
\hline Tourist demand & $\begin{array}{l}\text { Solvency requirement for the purchase of travel services } \\
\text { in the Russian Federation for the period }\end{array}$ & person \\
\hline Tourist spending & Average spending per tourist per day & ruble / day \\
\hline Number of tourists & $\begin{array}{l}\text { Total number of tourists in the Krasnodar region for the } \\
\text { period }\end{array}$ & person \\
\hline Currency rate & Average nominal exchange rate of dollar & ruble / \$ \\
\hline $\begin{array}{l}\text { Cost of foreign } \\
\text { analogues }\end{array}$ & The average cost of travel to Turkey (per day) & ruble / day \\
\hline Price attractiveness & $\begin{array}{l}\text { Relative attractiveness of the resorts of Krasnodar region } \\
\text { by the price criteria }\end{array}$ & - \\
\hline $\begin{array}{l}\text { Recreational } \\
\text { attractiveness }\end{array}$ & $\begin{array}{l}\text { Relative attractiveness of the resorts of the Krasnodar } \\
\text { region by the recreational resources criteria }\end{array}$ & - \\
\hline $\begin{array}{l}\text { Accomodation } \\
\text { facilities }\end{array}$ & Number of places in sanatoriums, hotels etc. & - \\
\hline $\begin{array}{l}\text { Need for health } \\
\text { services }\end{array}$ & Interest of the tourists who want to get medical services & $\%$ \\
\hline $\begin{array}{l}\text { Number of tourists } \\
\text { with health services }\end{array}$ & $\begin{array}{l}\text { Number of tourists in the Krasnodar region for the period } \\
\text { that want to get medical services }\end{array}$ & person \\
\hline $\begin{array}{l}\text { Cost of tourist } \\
\text { services }\end{array}$ & $\begin{array}{c}\text { Average cost of stay in the sanatorium of the Krasnodar } \\
\text { Territory (including transport services) }\end{array}$ & ruble / day \\
\hline $\begin{array}{l}\text { Sanatorium branch } \\
\text { income }\end{array}$ & $\begin{array}{c}\text { Gross profit of sanatorium branch enterprises of } \\
\text { Krasnodar Region }\end{array}$ & ruble \\
\hline $\begin{array}{c}\text { Investments in } \\
\text { recreational } \\
\text { resources }\end{array}$ & Gross investment in recreational resources & ruble \\
\hline $\begin{array}{l}\text { Investments in } \\
\text { accommodation } \\
\text { facilities } \\
\end{array}$ & $\begin{array}{l}\text { Gross investment in the deployment and upgrade of } \\
\text { accommodation }\end{array}$ & ruble \\
\hline GRP & Gross regional product of Krasnodar Region & ruble \\
\hline $\begin{array}{l}\text { Income per capita } \\
\text { KR }\end{array}$ & Average cash income per capita in the Krasnodar region & ruble \\
\hline Investments & Gross investment in the Krasnodar Territory & ruble \\
\hline
\end{tabular}

Based on retrospective statistical data the correlation regression analysis of considered model has been carried out. Data connections and power (in the presence of quantitative statistics) are presented in Table 2. 
Table 2. Connections of cognitive model

\begin{tabular}{|c|c|c|c|}
\hline Indicator & Description & Type & Unit of measurement \\
\hline R 1 & GDP - Income per capita & Direct & $\begin{array}{c}\text { correlation coefficient } 0,78 \text { - strong } \\
\text { direct relationship }\end{array}$ \\
\hline R 2 & GDP - Life expectancy & Direct & $\begin{array}{c}\text { correlation coefficient } 0.72 \text { - strong } \\
\text { direct relationship }\end{array}$ \\
\hline R 3 & GDP - Morbidity & Direct & $\begin{array}{l}\text { correlation coefficient } 0.32 \text { - weak } \\
\text { direct relationship }\end{array}$ \\
\hline R 4 & GDP - GRP & Direct & $\begin{array}{c}\text { correlation coefficient } 0,82 \text { - strong } \\
\text { direct relationship }\end{array}$ \\
\hline R 5 & $\begin{array}{l}\text { Income per capita - Household } \\
\text { spending }\end{array}$ & Direct & $\begin{array}{l}\text { correlation coefficient } 0.95 \text { - very } \\
\text { strong direct relationship }\end{array}$ \\
\hline R 6 & $\begin{array}{c}\text { Life expectancy - Need for health } \\
\text { services }\end{array}$ & Direct & $\begin{array}{l}\text { correlation coefficient } 0.91 \text { - strong } \\
\text { direct relationship }\end{array}$ \\
\hline R 7 & Morbidity - Need for health services & Direct & $\begin{array}{l}\text { correlation coefficient } 0.73 \text { - strong } \\
\text { direct relationship }\end{array}$ \\
\hline R 8 & Sanatorium branch income - GRP & Direct & \\
\hline R 9 & GRP - Investments & Direct & $\begin{array}{l}\text { correlation coefficient } 0.94 \text { - very } \\
\text { strong direct relationship }\end{array}$ \\
\hline R 10 & GRP - Income per capita KK & Direct & $\begin{array}{l}\text { correlation coefficient } 0.96 \text { - very } \\
\text { strong direct relationship }\end{array}$ \\
\hline R 11 & $\begin{array}{c}\text { Household spending - Tourist } \\
\text { demand }\end{array}$ & Direct & \\
\hline R 12 & $\begin{array}{c}\text { Household spending - Tourist } \\
\text { spending }\end{array}$ & Reverse & $\begin{array}{c}\text { correlation coefficient }-0.49- \\
\text { noticeable reverse relationship }\end{array}$ \\
\hline R 13 & Tourist demand - Number of tourists & Direct & \\
\hline R 14 & $\begin{array}{l}\text { Tourist spending - Sanatorium branch } \\
\text { income }\end{array}$ & Direct & \\
\hline R 15 & $\begin{array}{l}\text { Need for health services - Number of } \\
\text { tourists with health services }\end{array}$ & Direct & \\
\hline R 16 & $\begin{array}{c}\text { Number of tourists - Number of } \\
\text { tourists with health services }\end{array}$ & Direct & \\
\hline R 17 & Currency rate - Price attractiveness & Direct & \\
\hline R 18 & $\begin{array}{c}\text { Cost of foreign analogues - Price } \\
\text { attractiveness }\end{array}$ & Direct & \\
\hline R 19 & $\begin{array}{c}\text { Price attractiveness - Number of } \\
\text { tourists } \\
\end{array}$ & Direct & \\
\hline $\mathrm{R} 20$ & $\begin{array}{l}\text { Recreational attractiveness - Number } \\
\text { of tourists }\end{array}$ & Direct & \\
\hline $\mathrm{R} 21$ & $\begin{array}{l}\text { Accomodation facilities - Number of } \\
\text { tourists }\end{array}$ & Direct & $\begin{array}{c}\text { correlation coefficient } 0.17 \text { - weak } \\
\text { direct relationship }\end{array}$ \\
\hline R 22 & $\begin{array}{l}\text { Number of tourists - Sanatorium } \\
\text { branch income }\end{array}$ & Direct & \\
\hline R 23 & Investments - Cost of tourist services & Direct & $\begin{array}{c}\text { correlation coefficient }-0.32 \text { weak } \\
\text { reverse relationship }\end{array}$ \\
\hline R 24 & $\begin{array}{l}\text { Investments - Investments in } \\
\text { accommodation facilities }\end{array}$ & Direct & $\begin{array}{c}\text { correlation coefficient } 0.9 \text { - strong } \\
\text { direct relationship }\end{array}$ \\
\hline $\mathrm{R} 25$ & $\begin{array}{c}\text { Investments - Investments in } \\
\text { recreational resources } \\
\end{array}$ & Direct & $\begin{array}{l}\text { the correlation coefficient of } 0.9 \text { - } \\
\text { strong direct relationship }\end{array}$ \\
\hline R 26 & $\begin{array}{c}\text { Income per capita KR - Cost of } \\
\text { tourist services }\end{array}$ & Uncertain & \\
\hline R 27 & $\begin{array}{c}\text { Investments in accommodation } \\
\text { facilities - Accomodation facilities }\end{array}$ & Direct & \\
\hline R 28 & $\begin{array}{c}\text { Investments in recreational resources } \\
\text { - Recreational attractiveness }\end{array}$ & Direct & \\
\hline R 29 & $\begin{array}{c}\text { Cost of tourist services - Price } \\
\text { attractiveness }\end{array}$ & Reverce & \\
\hline
\end{tabular}


The relations having weak force have been removed from model. The model equations are constructed, or by regression analysis (if the specified indicator has reliable statistics), or by method of an expert assessment (in the absence of statistics in the public domain). All monetary indicators are displayed in 2011 prices, which is achieved by dividing the nominal value of the indicator on the accumulated inflation rate. To increase the level of confidence in the results of the simulation formal verification procedures were made.

The model verification is carried out to improve the model and test its rationale validity, ie how well the resulting model describes the behaviour of the modelled system. During that procedure model structure and parameters (for example, entry conditions and constants) can be specified, the model is being calibrated. Creation of a similar model for the entire economy of the region was presented in [12].

\subsection{Forecasting}

Based on the model described above, we forecast the tourist flows in the Krasnodar Territory in the medium term.

All the initial data correspond to the development of the system in the period from 2006 to 2017. The modelling step is 1 year; the modelling horizon is 2022 .

The results of the forecast are shown in Fig. 2, 3 and 4.

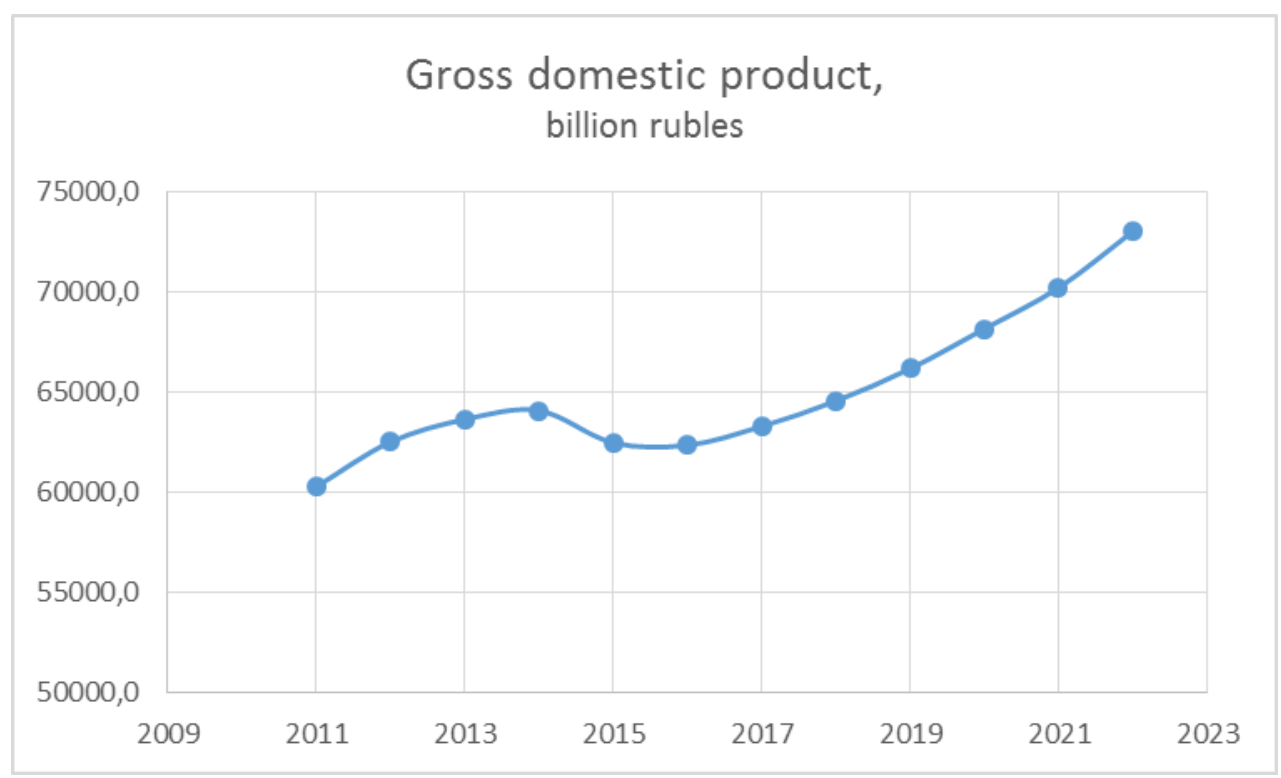

Fig. 2. Results of modelling on the indicator "Gross domestic product" 


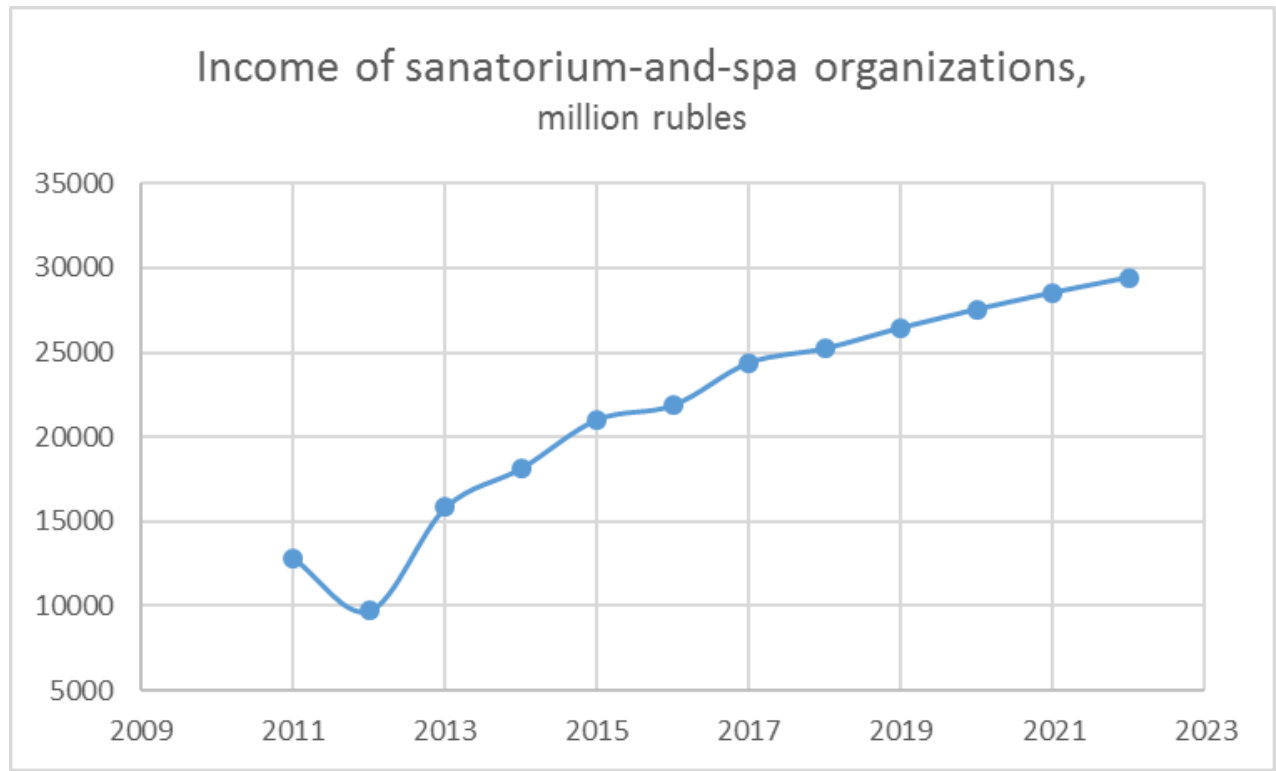

Fig. 3. The results of modelling on the indicator "Income of sanatorium-and-spa organizations"

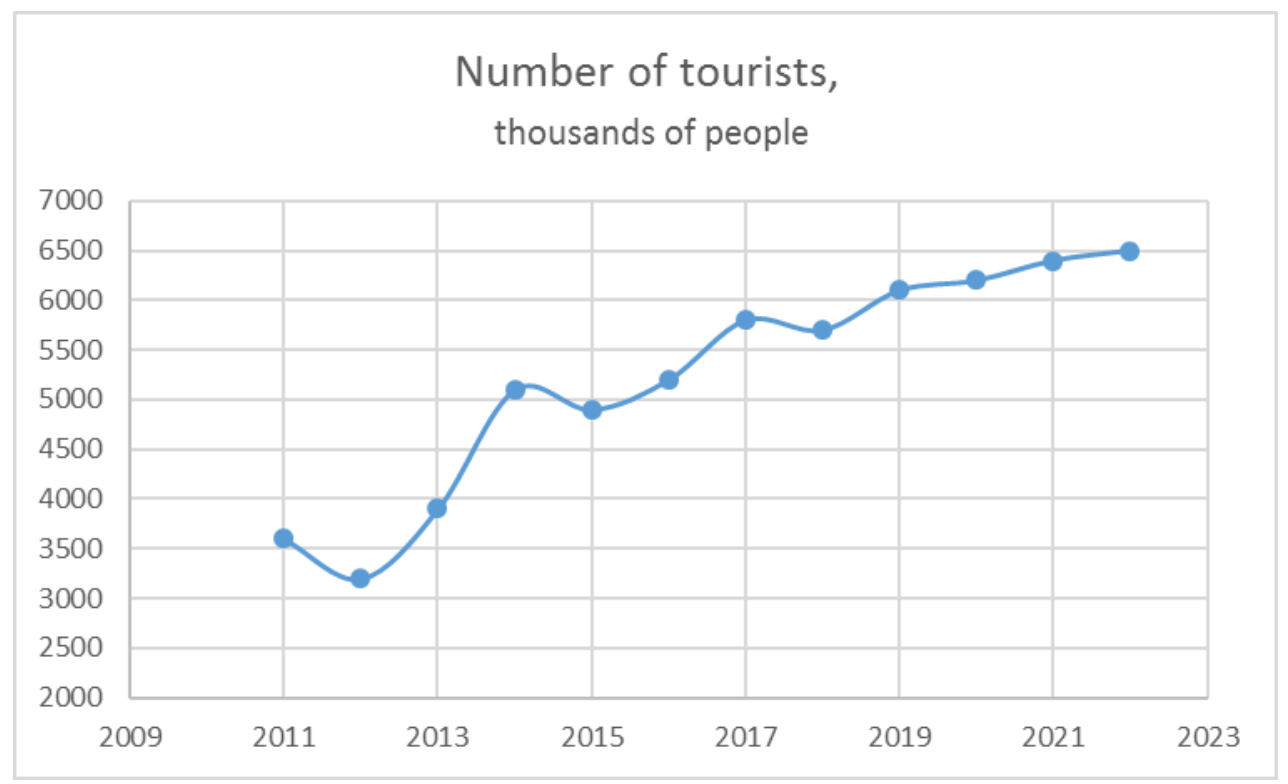

Fig. 4. The results of modelling on the indicator "Number of tourists"

As can be seen from the above figures, GDP in the prices of 2011 is monotonously increasing, almost 1.2 times in 12 years. The number of tourists demonstrates more complex dynamics. The initial trend for the decline in the number of tourists is reversed in 2012 , because of change in the amount and direction of investment in the spa sector (in particular, the creation of recreational resources for the 2014 Winter Olympics). However, the next growth slows down and goes into a fall, reaching in 2015 a mark of 4.9 million tourists. This circumstance is caused by the aggravation of price competition with resorts by analogues (Turkey, Egypt). 
Thus, based on the forecast presented above, one of the main problems of resorts in the Sochi-city is the relative appreciation of the cost of recreation, together with the strengthening of the real exchange rate of the ruble.

\section{Results}

Summarizing, we can say that the research of tourism demand in the Sochi-city is relevant. It can be considered that the optimal method of modelling urban socio-economic systems is simulation due to the stochastic character of the object and a complex multi-loop structure. The medium-term forecast constructed model shows that key factor influencing the market of tourist services in Sochi is price competition of inexpensive foreign resorts.

The practical importance of research is defined by possibility of usage the theoretical analysis results and scientifically well-founded recommendations about increase of efficiency of state regulation of development of the regional economic system of a cityresort Sochi.

\section{References}

1. L. Dwyer, P. Forsyth, W. Dwyer, Tourism economics and policy (Br, Ch.View. 2010).

2. H. Song, G. Li, Tourism demand modelling and forecasting-A review of recent research. Tour. Man. 29.2 (2008)

3. G. E. P. Box, G. M. Jenkins, G. C. Reinsel, Time series analysis: Forecasting and control (2013).

4. S. F. Witt, C. A. Witt. Forecasting tourism demand: A review of empirical research. Int. J. of F. 11.3 (1995)

5. F. Chan, C. Lim, M. McAleer. Modelling multivariate international tourism demand and volatility. T. M. 26(3) (2005)

6. A. Deaton, J. Muellbauer. An almost ideal demand system. The Am. Ec. review, 70(3) (1980)

7. D. Rutkovskaya, L. Rutkovskiy, M. Pilinskiy. Neyronnyie seti, geneticheskie algoritmyi i nechetkie sistemyi. (Moscow, 2003)

8. C.J.S.C. Burger, M. Dohnal, M. Kathrada, South Africa. 22(4) (2001)

9. S.C. Kon, L.W. Turner. Neural network forecasting of tourism demand. 11(3) (2005)

10. A. Palmer, J.J. Montano, A. Sesé. Designing an artificial neural network for forecasting tourism time series. T. M. 27(5) (2006)

11. M. Hernández-López. Future tourists' characteristics and decisions: The use of genetic algorithms as a forecasting method. T. Ec. 10(3) (2004)

12. A. Vetitnev, A. Kopyirin, A. Kiseleva. System dynamics modelling and forecasting health tourism demand: the case of Russian resorts. C. Iss. in T. 19(7) (2016) 